\title{
BMJ Open Understanding the cost of care of type 2 diabetes mellitus - a value measurement perspective
}

\author{
Gerardine Anne Doyle (10 , ${ }^{1,2}$ Shane O'Donnell, ${ }^{1,2}$ Kate Cullen, ${ }^{1}$ Etáin Quigley, ${ }^{3}$ \\ Sarah Gibney, ${ }^{4,5}$ The Diabetes Literacy Consortium
}

To cite: Doyle GA,

O'Donnell S, Cullen K, et al. Understanding the cost of care of type 2 diabetes mellitus - a value measurement perspective. BMJ Open 2022;12:e053001. doi:10.1136/ bmjopen-2021-053001

- Prepublication history for this paper is available online. To view these files, please visit the journal online (http://dx.doi. org/10.1136/bmjopen-2021053001).

Received 10 May 2021 Accepted 16 November 2021

Check for updates

(c) Author(s) (or their employer(s)) 2022. Re-use permitted under CC BY-NC. No commercial re-use. See rights and permissions. Published by BMJ.

${ }^{1}$ College of Business, University College Dublin, National University of Ireland, Dublin, Ireland

${ }^{2}$ Geary Institute for Public

Policy, University College Dublin, National University of Ireland,

Dublin, Ireland

${ }^{3}$ Applied Research for Connected Health, University College Dublin, National University of Ireland, Dublin, Ireland

${ }^{4}$ Geary Institute for Public Policy, University College Dublin, Dublin, Ireland

${ }^{5}$ Department of Health and Children, Dublin, Ireland

Correspondence to

Professor Gerardine Anne Doyle; gerardine.doyle@ucd.ie

\section{ABSTRACT}

Objectives We explore the cost of care of type 2 diabetes mellitus (T2DM) using time-driven activity-based costing (TDABC) and connect that cost to resulting patient health outcomes.

Design We construct six care pathways varying from low-risk to high-risk patients over a 12-month cycle of care. We collect time, resource and cost data on activities in each care pathway and compute a time-driven estimate of cost. Use of patient outcome data highlights the health outcomes achieved.

Setting Primary, secondary and tertiary care.

Participants Medical staff involved in the care of patients with T2DM.

Primary and secondary measures Primary: resources consumed to provide T2DM care. Secondary: health outcomes for representative patient within each patient category.

Results By computing cost of T2DM care and associated complications of chronic kidney disease, active foot disease, moderate risk of active foot disease and myocardial infarction, we show that when patients develop acute complications, significant costs are incurred, as compared with the cost of maintaining a patient at low or moderate risk. Variance analysis further informs decision making by showing the need to have the right personnel doing the right tasks at the right time to control costs. Conclusions A TDABC approach facilitates an understanding of the drivers of cost in chronic illness care. Our paper highlights the stages in the care pathway where different settings, decision making and a more optimal use of resources could assist with achievement of better patient outcomes.

\section{INTRODUCTION}

Measuring medical outcomes has been a significant focus of healthcare management research to date. Measuring cost incurred to achieve those outcomes has received less attention. ${ }^{1}$ Time-driven activity-based costing (TDABC) has been suggested as a costing tool that can deliver the required clarity and inform a greater understanding of value in healthcare. ${ }^{2-10}$ Combined with outcome data, TDABC has the potential to improve decision making and thus sustain optimum

\section{Strengths and limitations of this study}

- First study to apply time-driven activity-based costing to type 2 diabetes mellitus care and first study to link these costs to patient health outcomes.

- A lead researcher is a person with diabetes. Their experience of living with the disease informed all aspects of the study from the research design, data collection, data analysis and reporting.

- Being an exploratory study, a small sample size facilitated a better understanding of the process of care and allowed for manual extraction of health outcome data from written files.

- Only clinical outcome data were available for this study. Future studies would include both clinical and patient-reported outcome measures.

health outcomes at a lower cost. TDABC has also been attributed to identifying process improvements, reducing process variations and identifying the optimal mix of clinical personnel for each step in the care pathway. ${ }^{1}$

The prior focus of TDABC has been on specific medical procedures in acute care hospital settings. ${ }^{1}$ This study brings the application of TDABC to an empirical setting looking at the chronic condition of type 2 diabetes mellitus (T2DM). T2DM is selected as the unit of analysis for a number of reasons. First, a detailed bottom-up cost analysis of T2DM has yet to be carried out. ${ }^{11}$ Second, diabetes is one of the major public health challenges of the 21st century, affecting approximately 59 million people within Europe and 463 million worldwide, a figure that is expected to rise to 700 million by $2045 .^{12}$ Third, it has been reported that diabetes medical care accounts for a disproportionate allocation of health service resources across the western world, causing at least US $\$ 760$ billion in health expenditure in $2019,10 \%$ of total adult care spend. ${ }^{12}$ Fourth, the more severe complications associated with T2DM are preventable; such prevention 
would lower the economic burden of a disease should their condition remain stable. In recent years, there has been increasing emphasis on shifting treatment away from acute settings towards integrated care. Indeed, many health systems, including Ireland, are seeking to strengthen care in the community and integrated care between the acute and community settings. ${ }^{13}$ Integrated care programmes can lead to improvements in the quality of care and resource use outcomes. ${ }^{14}$

This study captures costs of care for T2DM across primary, secondary and tertiary sectors beyond the acute phase, thus exploring integrated care pathways in the analysis. This is important from both a clinical and policy perspective as it facilitates a better understanding of the clinical care pathway and provides evidence-based data from which policy can be developed.

The aim of this study was to calculate the cost of care of T2DM across primary, secondary and tertiary care using TDABC. Qualitative and quantitative data were collected on the delivery of T2DM patient care across six low-risk, moderate-risk and high-risk patient profiles over a 12-month cycle of care. The resource cost for each activity along the process of care was calculated using TDABC techniques, which provides a $€ /$ min cost for the resources consumed. This study also explores the resulting health outcomes for our patient profiles. By comparing the overall costs of healthcare provision to the health outcome data for each patient profile, an understanding of the health outcomes achieved for the estimated cost of care was derived. Finally, investigative cost analysis highlighted the factors influencing cost variation across the different patient profiles.

The TDABC methodology enables each step of the care pathway to be made visible. Each visible step is recorded alongside who performs the step, how long it takes them to perform it, and any additional resources required. A calculation is then made related to each step. Each step is then linked, building a bottom-up, granular understanding of the care pathway. This approach provides a more accurate picture of the cost of care related to various patient types, presentation and complications when compared with other top-down costing methods. Furthermore, the linking of cost with health outcome data offers a novel approach to obtain an in-depth understanding of the true value, beyond economic, of healthcare delivery. ${ }^{1}$

The remainder of the paper is structured as follows. The research method and data collection are provided in the Methods section, followed by the Results section. We discuss those results in the Discussion section, highlight our study's limitations in section five and finally, conclude the paper in the Conclusion section.

\section{METHODS}

TDABC was chosen as a methodology as it enables detailed patient-level costs to be computed. ${ }^{11516}$ TDABC is particularly useful and informative when examining a chronic condition such as T2DM, as it can be applied
Table 1 Exemplar patients with type 2 diabetes: patient profiles

$\begin{array}{ll}\text { Patient profile 1 } & \begin{array}{l}\text { Stable patient with optimum glycaemic } \\ \text { control (no pre-existing complications) }\end{array} \\ \text { Patient profile 2 } & \begin{array}{l}\text { Stable patient with suboptimum glycaemic } \\ \text { control (no pre-existing complications) }\end{array} \\ \text { Patient profile 3 } & \text { Chronic kidney disease } \\ \text { Patient profile 4 } & \text { Active foot disease } \\ \text { Patient profile 5 } & \text { Moderate risk of active foot disease } \\ \text { Patient profile 6 } & \text { Myocardial infarction }\end{array}$

uniformly in the management of a condition that spans primary, secondary and tertiary healthcare settings-a key feature of the care of T2DM. ${ }^{11}$

There are seven steps in the TDABC methodology, as defined by Kaplan and Porter ${ }^{1}$ : (1) select the medical condition and/or patient population to be examined; (2) define the care value chain; (3) construct process maps of each activity in patient care delivery and identify the resources involved and any supplies used for the patient at each process step; (4) obtain time estimates for each process step; (5) estimate the cost of supplying each patient care resource; (6) estimate the practical capacity of each resource provided and calculate the capacity cost rate; and (7) compute the total costs over each patient's cycle of care. In this study, each of these steps were completed through a combination of semistructured interviews and standard surveying. Data were collected in five phases.

First, qualitative in-depth interviews (qualitative interviews were carried out between May and November 2015) were conducted with senior and key clinical staff at an Irish hospital to understand the characteristics of the patient population. The data from the interviews facilitated the categorisation of the patient population into six 'typical' patient profiles ('exemplar patient groups'). These patient profiles represent multiple levels of severity from low risk to those with increasing levels of complexity (table 1 presents the patient profiles). Vignettes related to each patient profile were also developed. Each vignette included basic clinical and demographic information as well as a detailed description of the nature and severity of the patient's condition on clinical presentation. ${ }^{17}$

The vignettes were used to conduct vignette-based interviews with clinical staff along the care pathway. Vignettebased interviewing generates data on decision making and thus provides the required data for this project, namely, decisions about who manages the patient, what tasks they perform on/with the patient, how long it takes them to perform such tasks, what additional resources they use to perform such tasks, and future management and/or referrals to other services. In this respect, vignette-based interviewing, using empirically developed vignettes that represent exemplar patients in a particular area, allows for the incremental development of a care pathway and a 
cataloguing of all the resources that feed into the process of care.

This approach allows for the process of care for each patient to be mapped out, and this was then validated by senior clinical staff. In this project, the pathway includes the key process steps and classifies the actors involved over a 12-month care cycle. The activity costing method considers capacity costs such as personnel time, facilities and equipment which are used directly by the patient to be a variable cost and captures the effect of process variation on cost. This patient-level costing approach assumes very few costs are in fact fixed costs. In addition to the calculation of the exemplar patient pathways, clinical outcomes related to a a sample of matching patients was extracted from manual patient charts and notes.

Second, typical times, activities and resources (TARs) used by the actors in each pathway are captured. ${ }^{18} \mathrm{~A}$ standard survey instrument was administered to key clinical and administrative staff at primary, secondary and tertiary levels via face-to-face semistructured interviews. The one-to-one interaction offered opportunities for the researchers to clarify the granular level of detail required in participants' responses. It also allowed for participants' perspectives on the causes of large time variations, duplications and other potential inefficiencies to be explored.

Third, a review of the care pathways with senior clinical staff was conducted to confirm activities and time estimates and to ensure their accuracy.

Fourth, once all the data relevant to TAR were collected, interviews were conducted with members of the finance department. Standard cost lists such as those available in other countries (eg, under the NHS in the UK) do not exist in Ireland and, therefore, the finance department within the hospital site played a critical role in providing overhead cost information that could not be obtained elsewhere. Following these interviews, the patient-level costs for each of the six patient profile pathways using material and resource costs, payroll costs for all relevant staff levels and administrative and management cost data were calculated. Illustrative process maps were created to highlight the most significant activities conducted by each healthcare professional in each care cycle.

Finally, health outcome data were extracted from the patient files and charts (online, manual records and notes) from matching patients related to each patient profile. At the time of data collection for this study, health outcome measures for T2DM had not yet been developed by the International Consortium for Health Outcomes Measurement (ICHOM). Therefore, health outcomes for each patient cohort were selected following discussions with the lead diabetes clinician (table 2) and with reference to the American College of Cardiology (ACC) / American Heart Association (AHA) guidelines (table 3). These guidelines inform the health outcomes for the assessment of macrovascular disease (10-year risk of heart disease or stroke using the ASCVD algorithm) and microvascular disease risks (eye disease (retinopathy), kidney disease (nephropathy) and foot disease (neuropathy)
Table 2 Health outcome measures as advised by lead clinician

\begin{tabular}{ll}
\hline Health outcome & Measured by \\
\hline Blood sugar control & $\begin{array}{l}\text { A1c=\% of haemoglobin coated } \\
\text { with sugar }\end{array}$ \\
\hline $\begin{array}{l}\text { Hypertension } \\
\text { Weight control }\end{array}$ & $\begin{array}{l}\text { Systolic blood pressure } \\
\text { Body mass index }\end{array}$ \\
\hline $\begin{array}{l}\text { Risk of cardiovascular } \\
\text { disease a }\end{array}$ & High-density lipoprotein levels \\
\hline $\begin{array}{l}\text { Risk of cardiovascular } \\
\text { disease b }\end{array}$ & $\begin{array}{l}\text { Total cholesterol (milimole of } \\
\text { cholesterol per litre of blood) }\end{array}$ \\
\hline $\begin{array}{l}\text { Risk of kidney disease } \\
\text { Severity of diabetes } \\
\text { complications }\end{array}$ & $\begin{array}{l}\text { Albumin:creatine ratio } \\
\text { Number of outpatient visits at acute } \\
\text { setting }\end{array}$ \\
\hline
\end{tabular}

using the Alc measure). This is the first study of costing the care of people with T2DM using the TDABC method and the first study to review these costs in light of the health outcomes achieved, and so it is a proof of concept study of measuring the value of the care delivered. Due to the small sample size for the health outcome data, we did not consider weighing the outcomes.

Indeed, the methodology selected ensures that double costing cannot occur whereby each exemplar patient cost is calculated according to the characteristics detailed within the vignettes. Each characteristic is individually

Table 3 American College of Cardiology/American Heart Association (ACC/AHA) end organ damage risk variables and macrovascular and microvascular risk measures

\begin{tabular}{ll}
\hline Disease risk variable & Health outcome measure \\
\hline $\begin{array}{l}\text { Macrovascular (10-year risk } \\
\text { of heart disease or stroke) }\end{array}$ & $\begin{array}{l}\text { Non-modifiable/modifiable } \\
\text { measures }\end{array}$ \\
\hline Age & $\begin{array}{l}\text { Non-modifiable } \\
\text { Gen-modifiable }\end{array}$ \\
\hline Race & Non-modifiable \\
\hline Total cholesterol & $\begin{array}{l}\text { Modifiable-total cholesterol } \\
\text { (mg/dL, ideal 170) }\end{array}$ \\
$\begin{array}{l}\text { High-density lipoprotein } \\
\text { cholesterol }\end{array}$ & $\begin{array}{l}\text { Modifiable (mg/dL, ideal 150) } \\
\text { Systolic blood pressure }\end{array}$ \\
$\begin{array}{l}\text { Diastolic blood pressure } \\
\text { Treated for high blood } \\
\text { pressure }\end{array}$ & $\begin{array}{l}\text { Modifiable-ideal } 80 \\
\text { Dodifiable-yes/no }\end{array}$ \\
\hline $\begin{array}{l}\text { Smoker } \\
\text { Microvascular disease risk } \\
\text { (retinopathy, nephropathy } \\
\text { and neuropathy) }\end{array}$ & $\begin{array}{l}\text { A1c=\% of haemoglobin } \\
\text { coated with sugar } \\
\text { Ideal for this patient } \\
\text { cohort is <7 (note: } \\
\text { age, comorbidities and } \\
\text { 'brittleness' affect A1c } \\
\text { targets) }\end{array}$ \\
\hline
\end{tabular}




\begin{tabular}{|c|c|c|}
\hline Respondent type & $\begin{array}{l}\text { Persons } \\
\text { interviewed } \\
\text { (n) }\end{array}$ & $\begin{array}{l}\text { Total } \\
\text { interviews } \\
\text { (n) }\end{array}$ \\
\hline Endocrinologist (clinical lead) & 1 & 2 \\
\hline Endocrinologist & 1 & 3 \\
\hline Nephrologist & 1 & 1 \\
\hline Registrar & 1 & 1 \\
\hline Diabetes nurse specialist & 4 & 4 \\
\hline $\begin{array}{l}\text { Podiatrist/nurse specialising in } \\
\text { foot care }\end{array}$ & 1 & 2 \\
\hline Administrators & 3 & 3 \\
\hline General practitioner & 1 & 1 \\
\hline Community nurse specialist & 1 & 1 \\
\hline Community dietician specialist & 1 & 1 \\
\hline Public health nurse & 1 & 1 \\
\hline Cardiologist & 1 & 1 \\
\hline Cardiac rehabilitation nurse & 1 & 1 \\
\hline Financial manager & 1 & 1 \\
\hline Total interviews performed & & 23 \\
\hline
\end{tabular}

costed in what might best be described as a building block. Each building block can then be used interchangeably to calculate various combinations of patient presentations and is thus a valuable way of calculating cost without falling foul of double costing.

\section{Study sample}

We determined the sample size in consultation with the lead diabetes consultant, who advised of the clinical, administrative and managerial staffing numbers and identified staff relevant to the study, based on their role in the process of care. Administrative and managerial staff were selected based on their position as staff members responsible for payroll or management of financial information. Clinical and non-clinical staff were identified on the basis of their role in the delivery of T2DM care within the care pathway or as a support to the delivery of these activities. Table 4 provides a summary of the respondent/ practitioner type, the number of people interviewed and number of interviews conducted. There were 14 respondent types included in the interview process and 23 interviews were carried out in total (more interviews were conducted than the number of respondent types as, in some cases, multiple interviews were conducted with the same individual and/or multiple individuals of the same respondent type were interviewed).

\section{Analytical approach}

Data (interview responses, survey reported activity time estimates, aggregated financial estimates and field notes) were taken from the study site for transcription, dataset preparation, data aggregation and analysis. All interviews were deidentified, collated, coded and analysed thematically. All information related to TAR was inputed into an aggregate Excel database for analysis given in online supplemental figure 1 .

Following the TDABC approach, we calculated a cost per patient for each care pathway over a 12-month period in two steps:

1. To calculate the capacity cost rate, the cost of all resources involved in each care pathway is determined. This cost includes personnel salaries, overheads, rent where relevant, equipment software, insurance, etc. This resource total is then divided by the actual practical capacity of the resources in the care pathway. Practical capacity is calculated as $80 \%$ of the overall working time, ${ }^{1}$ where $20 \%$ is attributed to breaks, training and annual leave. Where time-driven data are not available, we collect estimates of the cost of individual procedures from the hospital finance department or theatre.

The capacity cost rate is calculated by:

$$
\text { Capacity Cost Rate }=\frac{\text { Cost of Capacity Supplied }}{\text { Practical Capacity of Resource Supplied }}
$$

2. We then assign costs to each of the six patient care pathways using the capacity cost rates calculated in step one.

Finally, we carry out a quantitative investigation of the differences in consumption and pricing of labour resources for each patient profile using cost variance analysis on labour costs. ${ }^{14}$ This investigative analysis facilitates an exploration of the drivers of care and cost variances for differing patient complications of T2DM. We analyse health outcome data through the use of radar charts which allow simultaneous comparison across the multiple relevant outcome dimensions. These outcome data were based on (anonymised) patient records which were recorded on Tymax, a customised database for management of diabetes patients at the diabetes clinic in which the field work was conducted.

\section{Patient and public involvement}

One of our lead researchers is a person with diabetes and, as such, was involved in all aspects of the study spanning the research design, data collection, data analysis and dissemination to the wider diabetes community.

\section{RESULTS}

The findings of the study are divided into the following sections. First, a brief overview of the Irish context for T2DM care is provided, highlighting the integrated care model that is being pursued. Then, the six patient profiles examined within that context are presented and then discussed collectively, informed by investigative cost analysis and health outcome analysis.

\section{Irish context}

Under the direction of the National Clinical Programme for Diabetes in Ireland, the care pathways for patients with T2DM are being reoriented towards an integrated shared 


\begin{tabular}{|c|c|c|c|c|c|}
\hline Patient Profile 1 & Patient Profile 2 & Patient Profile 3 & Patient Profile 4 & Patient Profile 5 & Patient profile 6 \\
\hline $\begin{array}{l}\text {-Stable patient } \\
\text { with optimum } \\
\text { glycaemic } \\
\text { control (no pre- } \\
\text { existing } \\
\text { complications) } \\
\text { - Low risk, } \\
\text { uncomplicated } \\
\text {-Most common } \\
\text { profile (70-80\% } \\
\text { of T2DM } \\
\text { population } \\
\text { - Treatment cost } \\
\text { for } 12 \text { month } \\
\text { cycle of care } \\
\text { with optimal } \\
\text { control - €798 }\end{array}$ & $\begin{array}{l}\text {-Stable patient } \\
\text { with sub } \\
\text { optimum } \\
\text { glycaemic } \\
\text { control (no pre- } \\
\text { existing } \\
\text { complications) } \\
\text { - Low risk, } \\
\text { uncomplicated. } \\
\text { most common } \\
\text { profile (70-80\% } \\
\text { of T2DM } \\
\text { population). } \\
\text { - Treamtment } \\
\text { cost for 12 } \\
\text { month cycle of } \\
\text { care with sub- } \\
\text { optimal control- } \\
€ 1,169\end{array}$ & $\begin{array}{l}\text {-Chronic kidney } \\
\text { disease } \\
\text { - Common } \\
\text { complication } \\
\text { associated with } \\
\text { T2DM } \\
\text { - Treatment cost } \\
\text { for a } 12 \text { month } \\
\text { cycle of care - } \\
€ 3,791\end{array}$ & $\begin{array}{l}\text {-Active foot } \\
\text { disease } \\
\text { - Found to be } \\
\text { more common } \\
\text { amongst males } \\
\text { of lower } \\
\text { socioeconomic } \\
\text { status } \\
\text { - Common for the } \\
\text { early stages of } \\
\text { Active Foot } \\
\text { Disease to go } \\
\text { undiagnosed for } \\
\text { a number of } \\
\text { months } \\
\text { - Late diagnosis } \\
\text { increases cost } \\
\text {-Tretment cost } \\
\text { for } 12 \text { month } \\
\text { cycle of care- } \\
€ 3,933\end{array}$ & $\begin{array}{l}\text { - Moderate risk of } \\
\text { active foot } \\
\text { disease } \\
\text { - Assessment in } \\
\text { the community } \\
\text { - Vascular and } \\
\text { neurological } \\
\text { assessment and } \\
\text { inspection of the } \\
\text { feet } \\
\text {-Visit includes } \\
\text { education } \\
\text { - Treatment cost } \\
\text { for a } 12 \text { month } \\
\text { cycle of care - } \\
€ 4,865\end{array}$ & $\begin{array}{l}\text {-Myocardial } \\
\text { Infarction } \\
\text { - Treament cost } \\
\text { for } 12 \text { month } \\
\text { cycle of care - } \\
€ 21,926\end{array}$ \\
\hline
\end{tabular}

Figure 1 Hours of practitioner time incurred per patient profile and care pathway. T2DM, type 2 diabetes mellitus.

care model between primary, secondary and tertiary care. Uncomplicated stable patients are to be treated primarily at primary care clinics, with appropriate support from community diabetes nurse specialists and dieticians, while input from secondary care will be targeted towards patients with highly complex needs and/or at high risk of developing diabetes-related complications. Even patients at moderate risk of developing complications may be adequately managed at primary care level provided the appropriate community support services are in place to assist general practitioners (GPs) improving the selfmanagement outcomes of patients and provided additional specialist assistance exists for the monitoring of risk factors such as peripheral neuropathy, impaired kidney function, retinopathy, etc. Community nurse specialists dealing with complex patient cases should also have access to a multidisciplinary care team based in local hospitals so as to determine the best treatment for patients with these complex needs.

\section{Descriptive results of six patient profiles}

In this section, we provide descriptive results of our six patient profiles. We also provide the treatment cost (process of care and medication) for each patient profile over a 12-month care cycle (see figure 1 for a snap shot of the six patient profiles).

Patient profile 1: stable patient with optimum glycaemic control (no pre-existing complications)

The treatment cost for a 12-month care cycle for the patient with optimum control is $€ 798$, while a patient with suboptimal control costs $€ 1169$ for a 12-month care cycle.

Patient profile 2: stable patient with suboptimum glycaemic control (no pre-existing complications)

The treatment cost for a 12-month cycle of care for the patient with suboptimum control amounts to $€ 1169$. This can be accounted for by additional medication costs of antihyperglycaemic drugs (metformin) required to bring glucose levels within clinical targets.
Patient profile 3: chronic kidney disease (nephropathy)

Chronic kidney disease (nephropathy) is another common complication associated with T2DM. Our care pathway mapping and costing of activities indicate that the cost of treatment of diabetic chronic kidney disease for a 12-month care cycle in Ireland is estimated to be $€ 3791$.

\section{Patient profile 4: active foot disease (neuropathy)}

Patients who suffer from active foot disease are usually male, of lower socioeconomic status and with limited health literacy. In addition, they may also suffer from other preexisting comorbidities such as loss of vision and poor peripheral sensation, which makes it difficult for them to actively examine and take care of their own feet. Often they will be less inclined to attend health services due to a lack of awareness of the risk to their feet as a result of having diabetes or may not possess adequate financial resources to access such services. It is common for the early stages of active foot disease to go undiagnosed for a number of months for this particular cohort of patient, which explains the significant cost of care. Our care pathway mapping and costing of activities indicate that the cost of treatment of diabetic active foot disease in Ireland for a 12-month care cycle is estimated to be $€ 3933$.

\section{Patient profile 5: moderate risk of active foot disease}

Following the guidelines outlined by the National Diabetes Working Group for foot care in Ireland, we also examined the cost of a patient visiting a specialist podiatrist in the community up to four times a year at 20-30 min per consultation, which would include vascular and neurological assessments, inspection of the feet and ongoing education. The 12-month cost of this pathway is estimated to be $€ 4865$.

\section{Patient profile 6: myocardial infarction}

The final patient profile examined was myocardial infarction. At the time of the study, we had limited access to cardiac healthcare professionals to perform the required qualitative interviews. However, activity data for the care pathway mapping and costing of activities were collected. 
Table 5 Process of care and medication costs per patient profile over a 12-month care cycle

\begin{tabular}{|c|c|c|c|}
\hline Patient profile (n and name) & Process of care $(€)$ & Medications (€) & Total cost $(€)$ \\
\hline $\begin{array}{l}\text { 1: Stable patient with optimum glycaemic control (no pre-existing } \\
\text { complications) }\end{array}$ & 613 & 185 & 798 \\
\hline 3: Chronic kidney disease & 1027 & 2764 & 3791 \\
\hline 4: Active foot disease & 1288 & 2645 & 3933 \\
\hline 6: Myocardial infarction & 20317 & 1609 & 21926 \\
\hline
\end{tabular}

From these data, the cost of treatment of myocardial infarction in Ireland for a 12-month care cycle amounted to an estimated $€ 21926$.

\section{Further patient profile listed by our lead informant is peripheral retinopathy}

As one of the most common microvascular complications associated with diabetes, retinopathy is a key driver of cost within healthcare systems. ${ }^{18}$ As part of national strategic goals to reduce its cost burden, the Health Service Executive in Ireland recently introduced a diabetes retinal screening service (free for all patients) which is offered as part of routine care in local community settings and funded through a public-private partnership. Photographs of the eye, as well as analysis of the photograph, are carried out by specially trained non-medical professionals (known as 'graders'). If a serious retinopathy is detected, the patient will then be referred to an ophthalmologist for further assessment. As the diabetes retinal screening service is performed in a setting different from the site of our ethical approval for this study, the costing of this service was not possible.

Table 5 presents the process of care and medication cost for each of the six patient profiles in the study.

\section{Investigative cost variance analysis}

The cost difference between any two patient profiles can be analysed into two effects: a rate variance due to different capacity cost rates of resource and an efficiency variance due to different use of resource. There are a number of factors that were found to influence cost variation. First, patient profiles differed in duration and in the hours of practitioner time spent on each care pathway. This reflects an efficiency variance due to different quantities of total personnel used and suggests that total personnel time is a strong cost driver.

Second, mix of personnel skill used in providing the relevant patient care is a key cost driver. These findings suggest that personnel skill is a significant driver of cost. Given the high cost of some practitioners, a question arises whether some work could be shifted to a lower cost resource, for example, a medical assistant or a scribe (as in the USA).
Figure 2 shows the hours spent by each practitioner on each care pathway, highlighting the skill mix differential across care pathways.

Taking total cost per patient profile, the base patient profile was taken as that of the patient with stable glycaemic control, the low risk, uncomplicated patientpatient profile 1 . The key cost drivers identified were then compared with this baseline patient profile to explore the reasons for these variances. The key cost drivers for disease progression include the type of practitioner, practitioner hours used, the practical capacity rate of the skill mix, medications and consumables used. This reveals the complexity of cost behaviour and highlights the importance of disease prevention through patient monitoring and management at the community setting rather than at the acute setting.

\section{Health outcome analysis}

The use of radar charts in this study provides a visual depiction of the outcomes achieved for patients relative to costs incurred. A score of 100 on a radar chart represents ideal performance-lowest cost and better health outcomes. Figure 3 presents a radar chart illustrating simultaneously across the six patient profiles the outcomes achieved for patients with T2DM relative to the costs incurred over a complete cycle of care. The chart illustrates that those with the best health outcomes also have the lowest annual cost of care, that is, 'stable optimum' and 'suboptimum'

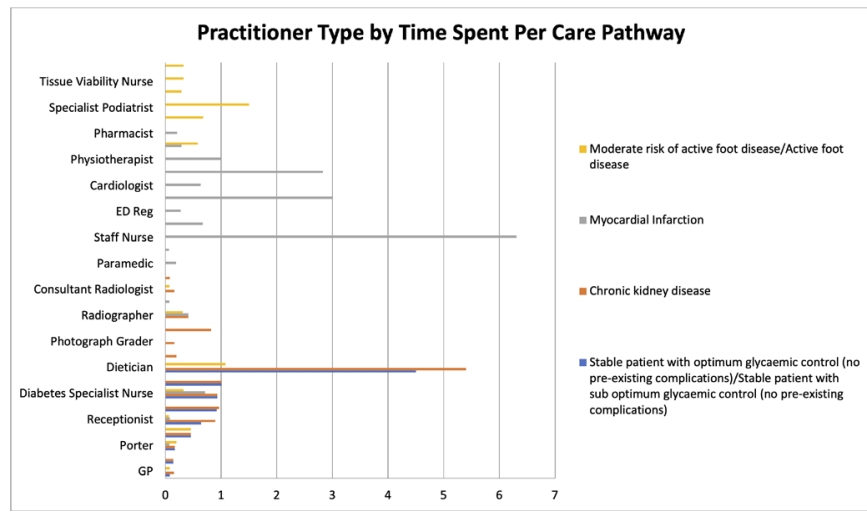

Figure 2 Hours spent by each practitioner on each care pathway. 


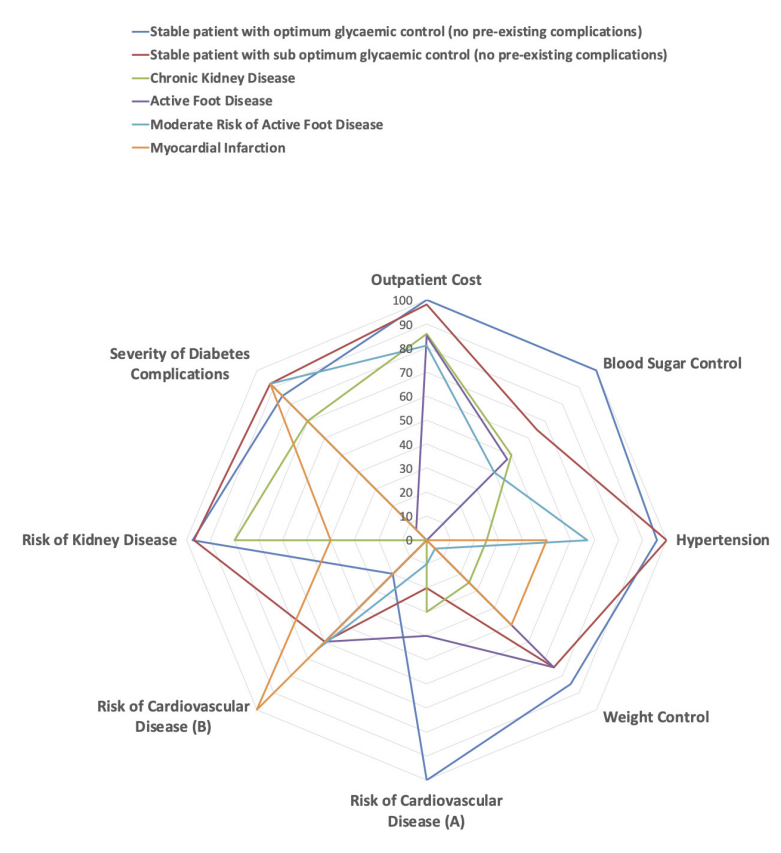

Figure 3 Outcomes and cost of care of patients with type 2 diabetes mellitus (a score of 100 represents ideal performance-better health outcomes and lowest cost).

glucose control. As the complications progress to chronic kidney disease, active foot disease, moderate risk of active foot disease and myocardial infarction health outcomes disimprove and the annual cost of care increases significantly. These findings illustrate the importance of investing in preventive care. A combination of enhanced patient self-management education and specialist care at the community level could help to maintain patients at a stable glycaemic control, thus ensuring better health outcomes for patients and lower costs for providers. These preventative actions in turn reduces the economic burden for national health services.

A second radar chart (figure 4) presents the health outcome data across each of the six patient profiles, for the macrovascular disease risk (using the ACC/AHA algorithm) and the microvascular disease risk (A1c measure) for patients with T2DM relative to the costs incurred over a complete cycle of care. The ACC/AHA algorithm enables the actual cardiovascular risk for each patient profile to be compared with the optimal risk, thereby estimating a measure of the modifiable risk. This radar chart highlights the lowest risk levels and lowest modifiable risks for the most stable glycaemic control, also having the lowest annual cost of care. As complications progress to chronic kidney disease, active foot disease, moderate risk of active foot disease and myocardial infarction, the cost of care increases significantly. Active management of the condition, through a combination of patient self-management education and specialist care at the community level, is a key strategy for minimising such risks. Within the ACC/AHA algorithm, high blood pressure (diastolic and systolic measures), smoking and age

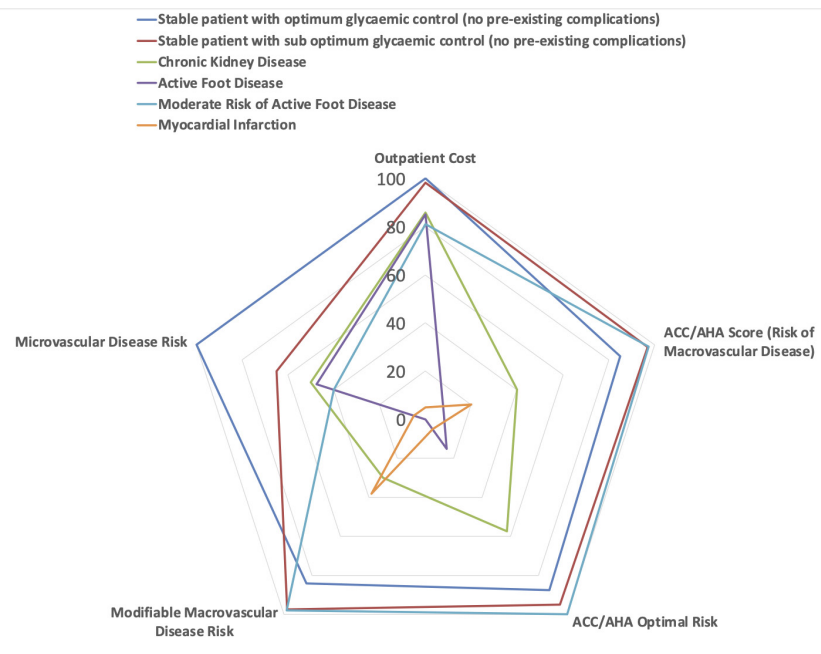

Figure 4 Cost and risks of macrovascular and microvascular disease for patients with T2DM (a score of 100 represents ideal performance-lowest risk and lowest cost). ACC, American College of Cardiology; AHA, American Heart Association.

significantly increased the risk of both macro and microvascular disease.

\section{DISCUSSION}

In this study, we explored and documented the care pathways for patients at different stages of T2DM over a 12 month care cycle. Six different hypothetical patient profiles were constructed ranging from low to high risk. Adopting the bottom-up costing approach inherent within TDABC provided us with the flexibility required to build an accurate cross comparison of the costs of treating complications as the patient moves though the various stages of risk progression.

Furthermore, it was demonstrated that the cost of maintaining a patient at low or even moderate risk (before progressing to the acute stage of illness) does not represent a significant expense per patient and is a fraction of what is currently being spent on acute complications. The cost data for each patient profile (table 5) reveal that the cost of patients with stable glycaemic control having a low risk of complications is $3 \%$ of the cost of those developing myocardial infarction and $16 \%$ of the cost of moderate risk of foot disease arising as a consequence of T2DM.

The experts interviewed in this study argue that the best way to prevent the onset of the acute complications is to invest in community and primary care systems where the self-management capabilities of patients can be improved through education. Other research provides evidence of the low cost per patient of diabetes self-management education when delivered in the community. ${ }^{11}$ These are the areas of the healthcare system where resources are least distributed and care is most fragmented, and yet the areas of the healthcare system where positive patient outcomes can be achieved at an early stage of care, while reducing the economic burden 
on the system. Each of the experts interviewed outlined how a lack of knowledge surrounding diabetes in the community meant that GPs were often over-referring their patients to specialists within the secondary care system, resulting in them being placed on a waiting list while their condition worsened. It could be argued that to increase diabetes selfmanagement capabilities among patients, there is a need to address fundamental deficits in diabetes literacy among health professionals and other practitioners in the community, as well as the patients themselves.

In this study, we combined patient outcome data with the TDABC treatment cost data to demonstrate the value equation and value-based healthcare, furthering prior research. ${ }^{1}$ The analysis of the health outcome data for T2DM relative to the costs incurred over a cycle of care presents the case for keeping patients at the lowest risk of complications and provides enhanced data for decision making surrounding optimal healthcare delivery alongside patient self-management education.

\section{Limitations}

First, TDABC is a relatively new method in terms of healthcare costing with limited studies investigating the costs of chronic conditions such as diabetes. As a result, there were limited guidelines surrounding the collection of activity and process step data in non-acute settings. It was necessary for the researchers to develop novel data collection tools to meet the requirements of TDABC. Second, being an exploratory study, a small sample size was appropriate to better understand the process of care and to extract clinical health outcome data from patient records. Third, it has been suggested that value can only be determined when there is visibility of both costs and clinical and patient-reported outcomes. ${ }^{1}$ For this study, only clinical outcome data were available for analysis. We argue that linking both clinical and patient-reported outcome (functionality) data with cost data is essential for true decision making and to extend the concept of patient-centred 'value' in healthcare beyond the dominant biomedical sphere. Future studies can now draw on the ICHOM type 1 and type 2 diabetes in adults standard set. Furthermore, it is important to note that microvascular and macrovascular complications tend to cluster together, particularly for older people with diabetes and a history of suboptimal control. However, in order to establish a cost per complication, it was necessary to look at each profile in isolation. Future studies could build on the findings of this study by calculating the costs of multiple complications and comorbidities.

\section{CONCLUSION}

This study contributes to the body of literature on valuebased measurement and delivery in healthcare. It is the first study, to our knowledge, to apply TDABC to the chronic illness of T2DM and to span both the acute and community sectors. Analysis of the process maps suggests opportunities for enhanced decision making on the mix of personnel used, in efforts to achieve greater clinical effectiveness and efficiency in healthcare delivery. Demonstrating the cost of the six most prevalent T2DM patient profiles when combined with patient outcomes and macrovascular disease risk, provides ground-breaking data to inform the transformation of health service design around chronic conditions for a more integrated and value based service delivery.

Acknowledgements This article was partly undertaken within the Diabetes Literacy project supported by grant FP7-Health-2012-Innovation-1/306186 of the European Commission. The authors would like to thank the partners of the Diabetes Literacy Consortium for their support in conducting this study. The authors also thank all staff involved of St Vincent's University Hospital Group, without whom this study would not have been possible. Special thanks are due to our Diabetes Lead Consultant who gave so generously of their support and time to enable the study to be undertaken.

Collaborators The Diabetes Literacy Consortium consists of the following members: Université Catholique de Louvain, Belgium: Stephan Van den Broucke, Gerard Van der Zanden, Marie Housiaux, Louise Schinckus. Technische Universität Dresden, Medical Faculty, Germany: Peter Schwarz, Gabriele Mueller, Henna Riemenschneider, Sarama Saha. University College Dublin, Ireland: Gerardine Doyle, Shane 0'Donnell, Etain Quigley, Kate Cullen, Sarah Gibney. Gesundheit Österreich GmbH, Austria: Jürgen Pelikan, Florian Röthlin, Kristin Ganahl, Sandra Peer. Maastricht University, Department of International Health, The Netherlands: Helmut Brand, Kristine Sörensen, Timo Clemens, Marjo Campmans. University of Southampton, UK: Lucy Yardley, Ali Rowsell, Ingrid Muller, Victoria Hayter. Clalit Health Services, Israel: Diane Levin-Zamir, Ziv Har-Gil. University of California at San Francisco, USA: Dean Schillinger, Courtney Lyles, Lina Tieu. Taipei Medical University, Taiwan: Peter Chang, Candy Kuo, Alice Lin, Duong Van Tuyen, Becky Sun. Aarhus University, Denmark: Helle Terkildsen Maindal, Jill Rowlands, Ulrik Martensen.

Contributors GAD initially proposed the study. GAD and SG specified the methodology. KC carried out the cost analysis. All authors contributed to the protocol design, data collection and analysis plan. $E Q$ and SO'D wrote the initial manuscript, and all authors contributed to improving the manuscript. All authors approved the final manuscript. GAD is acting as guarantor of data.

Funding This study is part of the Diabetes Literacy project supported by the European Commission (grant FP7-Health-2012-Innovation 1/306186).

Competing interests None declared.

Patient and public involvement Patients and/or the public were involved in the design, conduct, reporting or dissemination plans of this research. Refer to the Methods section for further details

\section{Patient consent for publication Not applicable.}

Ethics approval This study involves human participants, but an ethics committee or institutional board exempted this study. Full ethical approval was granted by the St Vincent's University Hospital Group Limited Ethics and Medical Research Committee on 19 February 2014 (no ID number and so this approval is available on request) and by the research ethics committee of the Office of Research Ethics University College Dublin (ID Number HS-E-13-95). Participants gave informed consent to participate in the study before taking part.

Provenance and peer review Not commissioned; externally peer reviewed.

Data availability statement Data are available upon reasonable request. All data relevant to the study are included in the article or uploaded as supplementary information. The Excel spreadsheets showing how the individual activity costs were aggregated are available should they be requested.

Open access This is an open access article distributed in accordance with the Creative Commons Attribution Non Commercial (CC BY-NC 4.0) license, which permits others to distribute, remix, adapt, build upon this work noncommercially, and license their derivative works on different terms, provided the original work is properly cited, appropriate credit is given, any changes made indicated, and the use is non-commercial. See: http://creativecommons.org/ licenses/by-nc/4.0/.

ORCID iD

Gerardine Anne Doyle http://orcid.org/0000-0001-8516-4431 


\section{REFERENCES}

1 Kaplan RS, Porter ME. How to solve the cost crisis in health care. Harv Bus Rev 2011;89:46-52.

2 Porter ME. A strategy for health care reform. New England J Med 2009.

3 Porter ME. A strategy for health care reform - toward a value-based system. N Engl J Med Overseas Ed 2009;361:109-12.

4 Porter ME, Lee TH. The strategy that will fix health care. Harvard business Review 2013;91:1-19.

5 Kaplan RS. Improving value with TDABC. Healthc Financ Manage 2014;68:76-84

6 Kaplan RS, Witkowski ML. Better accounting transforms health care delivery. Accounting Horizons 2014;28:365-83.

7 Kaplan RS, Haas DA. How not to cut health care costs. Harv Bus Rev 2014;92,): :116-22. no. 11

8 Kaplan RS, Witkowski M, Abbott M, et al. Using time-driven activity-based costing to identify value improvement opportunities in healthcare. J Healthc Manag 2014;59:399-412.

9 Porter ME, Lee TH. Why strategy matters now. N Engl J Med 2015;372:1681-4.

10 Porter ME, Kaplan RS. How to pay for health care. Harv Bus Rev 2016;94:88-100.
11 Doyle G, O'Donnell S, Quigley E, et al. Patient level cost of diabetes self-management education programmes: an international evaluation. BMJ Open 2017;7:e013805

12 International Diabetes Federation. IDF diabetes atlas. Brussels: International Diabetes Federation, 2019.

13 Busetto L, Luijkx KG, Elissen AMJ, et al. Intervention types and outcomes of integrated care for diabetes mellitus type 2: a systematic review. J Eval Clin Pract 2016;22:299-310.

14 Ellen Nolte. Evidence supporting integrated care in Amelung. In: Stein V, Goodwin N, Balicer R, et al, eds. Handbook integrated care. Basel, Switzerland: Springer, 2017: 25-38.

15 Kaplan RS, Anderson SR. The innovation of time-driven activitybased costing. Journal of Cost Management 2007;21:5-15.

16 Erhun F, Mistry B, Platchek T, et al. Time-driven activity-based costing of multivessel coronary artery bypass grafting across national boundaries to identify improvement opportunities: study protocol. BMJ Open 2015;5:e008765.

17 Quigley E, Michel A, Doyle G. Vignette-Based interviewing in the health care space: a robust method of vignette development, 2020 SAGE research methods cases: medicine and health. London: SAGE Publications Ltd, 2020.

18 Quigley E, O'Donnell S, Doyle G. Time-driven activity-based costing: a step-by-step guide to collecting patient-level health care costs. London: SAGE Research Methods Cases, 2020. 